\title{
Divide et impera!
}

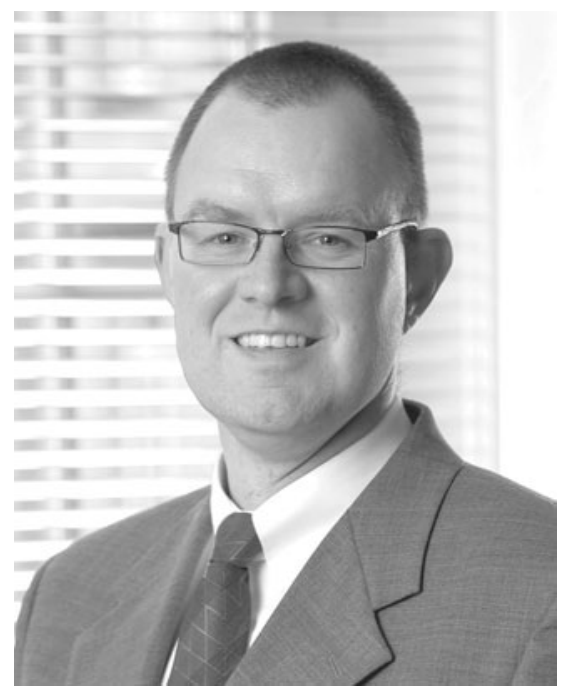

Informatiker denken bei der Redewendung "Divide et impera!" - „Teile und herrsche!" - häufig (und vielleicht mit etwas Wehmut) an ihre ersten Vorlesungen zurück, und innen fallen elementare Algorithmen wie die Binärsuche (die angeblich schon von den Babyloniern benutzt wurde), Quicksort oder vielleicht sogar die Schnelle FourierTransformation ein.,Nicht-Informatiker' assoziieren damit vielleicht eher Niccolò Machiavelli, der diese Formulierung 1532 prägte, als er in seinem Werk "Der Fürst" den Medici empfahl, wie sie ihre Herrschaft am wirksamsten ausüben sollten. Auch wenn diese Maxime schon 1.500 Jahre zuvor im Römischen Reich gelebte Praxis war, sind antike Quellen für das Zitat aus dieser Zeit nicht belegt.

Modern ist das Prinzip nach wie vor. So legt die inherente Komplexität vieler heutiger Aufgabenstellungen nahe, sich dieser Strategie des Aufteilens komplexer Herausforderungen in kleinere Teilaufgaben zu bedienen, um dieser Probleme überhaupt noch Herr zu werden. Untersuchungen des erst kürzlich verstorbenen amerikanischen Psychologen George A. Miller legen nahe, dass wir in der Regel mit mehr als sieben Zielen, die wir gleichzeitig verfolgen, überfordert sind (die „Millersche Zahl“, 1956).

Hohe Komplexität ist eine grundsätzliche Eigenschaft vieler Fragestellungen der ITSicherheit, insbesondere der Sicherheit von (Web-)Anwendungen. Über einen recht langen Zeitraum wurde Wissen zu Fragestellungen von IT und auch deren Sicherheit vor allem in Expertenkreisen gesammelt und geteilt. Eine Publikation dieses Wissens erfolgte nur auszugs- und schrittweise, wodurch Angreifer lange Zeit große Vorsprünge vor den Verteidigern hatten, gerade im Bereich von Webanwendungen.

Vor etwa zehn Jahren begann eine Gruppe von Sicherheitsexperten in den USA, Grundsätze der Open Community, denen das Prinzip „Divide et impera!“ zu Grunde liegt, auf Fragestellungen der Sicherheit von Webanwendungen zu übertragen. Sie gründeten das "Open Source Web Application Project", heute besser bekannt unter dem Akronym OWASP. Seitdem hat die Aufteilung der Probleme der Websicherheit in beherrschbare Fragestellungen und deren offene Bearbeitung zu einer Vielzahl von Projekten und Dokumenten (durchaus unterschiedlichen Reifegrades und in variierender Qualität) geführt - auch in Deutschland. Vor allem aber sind zahlreiche Fragestellungen durch viele Fachleute, die freiwillig Ihr Know-How bereitstellen, intensiv beleuchtet worden. Es kann durchaus behauptet werden, dass durch diese intensive Bearbeitung vieler Detailfragen zur Anwendungssicherheit inzwischen eine breite Awareness für dieses Thema vorhanden ist. Mittlerweile stehen auch viele Ansätze zur konstruktiven Lösung der vielfältigen Herausforderungen in diesem Bereich zur Verfügung. Auch wenn einige davon durchaus noch verbesserungswürdig sind ist unbestritten, dass Hilfestellungen wie die „OWASP Top 10“ inzwischen als Industriestandard gelten.

In einem derart schnelllebigen Thema darf sich allerdings niemand auf den Lorbeeren ausruhen. Die sich rasant entwickelnden Technologien, gerade im Bereich von Webanwendungen, werden uns vor immer neue Sicherheitsprobleme stellen. Daher sollen die Beiträge dieses Schwerpunkthefts zur Sicherheit von Webanwendungen einerseits einen Einblick in die Arbeitsergebnisse von OWASP geben, und andererseits zur aktiven Beteiligung an der "Zerteilung und Beherrschung" der Sicherheitsherausforderungen von Webanwendungen einladen.

\section{Kai Jendrian}

